\title{
Matéria-prima da formação Corumbataí na região do pólo cerâmico de Santa Gertrudes, SP, com características naturais para fabricação de argila expandida
}

\author{
(Sedimentary rocks from Corumbataí formation \\ (Paraná basin, Brazil) with natural characteristics to \\ produce expanded clay lightweight aggregate)
}

\author{
M.M.T.Moreno ${ }^{1}$, A. Zanardo Zar R. R. Rocha, C.D. Roveri $^{2}$ \\ ${ }^{l} D P M-I G C E$, UNESP, Campus de Rio Claro \\ ${ }^{2}$ Núcleo de Engenharia de Minas, Instituto de Ciência e Tecnologia, \\ Universidade Federal de Alfenas - UNIFAL, Campus Avançado de Poços de Caldas \\ mmoreno@rc.unesp.br,azanardo@rc.unesp.br,Rogers.rocha@rochaforte.com.br, \\ carolina.roveri@unifal-mg.edu.br
}

\begin{abstract}
Resumo
Estudou-se um material da base da Formação Corumbataí, proveniente de uma mineração de argila, que apresenta restrições de uso em cerâmica devido à sua dureza e, principalmente, ao alto conteúdo de matéria orgânica. Verificou-se que o material apresenta características naturais ótimas para a fabricação de argila expandida diretamente a partir de fragmentos de rocha, mostrando comportamento piroplástico com expansão significativa se submetido à queima rápida. A caracterização da matéria-prima e do produto foi realizada mediante análise de carbono orgânico, difração de raios X, microscopia ótica e testes de queima. Foram determinadas as condições de queima para obter argila expandida utilizando forno de queima rápida e forno a rolos, ambos de laboratório, obtendo corpos com densidade variável (que podem chegar a valores menores que $0,5 \mathrm{~g} . \mathrm{cm}^{-3}$ ) até o limite de expansão. Esta densidade é obtida devido à formação de poros fechados e uma película externa vítrea, que proporcionam uma resistência mecânica alta aos fragmentos expandidos.

Palavras-chave: argilito, formação Corumbataí, argila expandida, agregado leve.
\end{abstract}

\begin{abstract}
This paper refers to the study of the material of the base of the Corumbatai formation (Parana Basin, Brazil) of a clay mine, which presents limits for its use in ceramic tiles in dry grinding process due to its hardness and, especially, the high content of organic matter in relation to the clay overlaid. The characterization of the raw material and the product was accomplished by organic carbon analysis, X-ray diffraction, optical microscopy and test-firing. Firing conditions were determined to get expanded clay, using fast firing static kiln and a continuous roller kiln, both from laboratory equipment, getting samples with variable density up

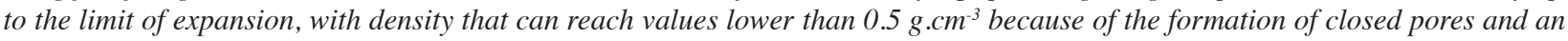
external vitreous foil which provide a high mechanical resistance to the particles.
\end{abstract}

Keywords: claystone, Corumbataí formation, expanded clay, lightweight aggregate.

\section{INTRODUÇÃO}

A maioria das indústrias de revestimento cerâmico localizadas na região de Rio Claro utiliza apenas matériasprimas obtidas da formação Corumbataí para composição de suas massas bases. Esta formação possui idade permiana e é uma unidade litoestratigráfica da bacia do Paraná, de natureza intracratônica, que evoluiu sobre a plataforma sul-americana. É constituída por um pacote sedimentar-magmático que documenta, de forma descontínua, o intervalo temporal entre o Neo-Ordoviciano e o Neo-Cretáceo do Gondwana [1]. Constitui o substrato de uma grande área, que abrange parte dos territórios dos estados de Minas Gerais, Mato Grosso do Sul, Mato Grosso, S. Paulo, Paraná, Santa Catarina e Rio Grande do Sul, além de partes do Paraguai, Argentina e Uruguai. A Formação Corumbataí foi alvo de inúmeras pesquisas de cunho geológico desde a década de 50, cujos objetivos convergem para a caracterização litoestratigráfica e identificação do paleoambiente deposicional desta formação [2-5]. A composição mineralógica destas rochas foi analisada $[6,7]$ por meio de difração de raios X aplicada a amostras de poços profundos. No final da década de 90 , em função do vertiginoso crescimento do Pólo Cerâmico de Santa Gertrudes, surgem pesquisas enfatizando a caracterização 
mineralógica, textural e química das rochas que compõem a formação Corumbataí, visando entender a influência destes atributos nas propriedades físicas da matéria-prima, durante o processo produtivo [8-13]. A formação Corumbataí é caracterizada pela presença de cores avermelhadas, amarronzadas e arroxeadas, com porções creme ou esverdeada, excetuando a porção basal onde a cor cinza é comum. Nas regiões próximas ao contato com a formação Irati (calcários e folhelhos), afloram siltitos illíticos duros e com teor alto de matéria orgânica, quando comparados à parte superior, não sendo adequadas para uso na fabricação de revestimentos pelas indústrias do pólo cerâmico de Santa Gertrudes [14]. Entretanto, testes expeditos de queima mostraram seu potencial para fabricação de argila expandida.

A composição da fração fina do material para a fabricação de argila expandida deve ser próxima à da illita para obter uma viscosidade adequada durante a queima, também deverá conter compostos que liberem gases e textura densa e compacta para retardar a liberação dos gases e vapores. Quanto à composição dos minerais acessórios, o ferro é importante para liberar oxigênio por reações redutoras, assim como o teor de alcalinos e alcalino-terrosos que determinam o grau de fusão [15].

Os agregados leves, em geral são muito usados na construção civil nos países mais desenvolvidos e caracterizam-se por ter estrutura de poros fechados, leveza, isolamento térmico, baixa absorção de água, inércia química e resistência à compressão. Os agregados leves manufaturados a partir de matéria prima argilosa muitas vezes são preparados passando pelos processos de moagem, umidificação, extrusão, corte, rolamento, secagem e queima em forno rotativo em temperaturas de $1100-1350{ }^{\circ} \mathrm{C}$ [16], sendo que em alguns casos são usados aditivos apropriados.

Os principais usos das argilas expandidas são: na construção civil para preparar concreto leve, para fabricação de blocos, pisos, guias, telhas e lajes de concreto, para determinados enchimentos leves, lavanderias industriais (estonagem de jeans), jardinagem, paisagismo e horticultura, além de outros usos de menor porte. O uso de agregado leve no concreto, além de reduzir o peso, faz com que este seja mais flexível, também a quantidade de aço necessária é menor devido ao menor peso, sendo também menores os custos operacionais e de transporte. Além disso, este produto é melhor isolante acústico e aumenta o seu poder como isolante térmico, tudo isto sem reduzir as propriedades do concreto. Por ter sido submetido a altas temperaturas é estável quimicamente e resistente a altas temperaturas. Sendo um produto que apresenta muitas vantagens de utilização, no Brasil não é utilizado amplamente devido ao alto custo e ao fato de haver praticamente um único fabricante, assim, esta matéria-prima torna-se importante, uma vez que sua composição natural permite a obtenção de argila expandida da melhor qualidade. Por outra parte, devido ao alto teor de matéria orgânica, não é utilizada na indústria cerâmica, pois o processo usado pela maioria das indústrias da região (mono queima rápida) não permite a liberação satisfatória dos gases provocando defeitos pontuais e coração negro, significando que atualmente não existe um uso direcionado para tal matéria-prima.

\section{MATERIAIS E MÉTODOS}

A pesquisa foi conduzida com as seguintes atividades: descrição geológica e coleta de amostras de argilas da base da formação Corumbataí, em duas camadas próximas ao contato com a formação Irati; análise mineralógica por difração de raios X (amostra total, fração argila, silte, tratamento térmico a $500{ }^{\circ} \mathrm{C}$, tratamento com etilenoglicol); análise química dos elementos maiores por espectrometria de fluorescência de raios $\mathrm{X}$ e do carbono orgânico quimicamente oxidável [17]; aquecimento de amostras a $500{ }^{\circ} \mathrm{C}, 550{ }^{\circ} \mathrm{C}$ e $600{ }^{\circ} \mathrm{C}$ por $2 \mathrm{~h}$ para determinar o intervalo de temperatura onde a matéria orgânica é eliminada; microscopia ótica na argila expandida e na matéria-prima natural utilizando secções delgadas normais e montagens com o pó utilizando líquidos de imersão de índice de refração conhecido. Numa segunda etapa as amostras foram britadas em britador de mandíbulas ajustado para obter fragmentos numa faixa cujo tamanho máximo foi de aproximadamente $5 \mathrm{~cm}$ na maior dimensão, secando os fragmentos de rocha a $110{ }^{\circ} \mathrm{C}$ por 1 $\mathrm{h}$ antes da queima. Esta foi realizada preliminarmente em forno estático de laboratório com temperatura programável, variando a temperatura máxima entre 1020 e $1120{ }^{\circ} \mathrm{C}$ visando estabelecer os limites para obtenção da máxima expansão e avaliação da temperatura a ser utilizada no forno contínuo a rolos.

A queima em forno contínuo de laboratório (a rolos) foi realizada sem separação por tamanho, exceto a fração mais fina $(<3 \mathrm{~mm})$ que não foi utilizada. A temperatura máxima na zona de aquecimento direto $(1,3 \mathrm{~m})$ foi $1130{ }^{\circ} \mathrm{C}$, percorrida a uma velocidade de $20 \mathrm{~cm} / \mathrm{min}$. Para acomodar os fragmentos foram usadas placas refratárias de $30 \times 30 \mathrm{~cm}^{2}$ introduzidas em seqüência e sem espaço entre elas, colocando $800 \mathrm{~g}$ sobre cada uma. Nos fragmentos expandidos foi medida a densidade aparente, além de testes de imersão em água por 30 min para avaliar à sua absorção.

\section{RESULTADOS E DISCUSSÃO}

A porção basal da formação Corumbataí, com aproximadamente $8 \mathrm{~m}$ de espessura, não é utilizada como matéria-prima-cerâmica por ser muito dura e conter carbono orgânico em excesso, provocando coração negro e defeitos pontuais nucleados por fragmentos maiores que não sofreram decomposição completa. Atualmente seu uso é para cascalhar estradas e preenchimento da cava, uma vez que tem que ser removido para a explotação do calcário dolomítico ao qual está sobreposto. Este tipo de material é observado em outras minas que tem como contato inferior a Formação Irati, da qual se extrai calcário para fins agrícolas, apresentando variações decorrentes do grau de alteração da rocha. Na mina, onde foi coletado o material estudado, o pacote de rochas argilosas da base da Formação foi dividido em duas camadas denominadas 1 (inferior) e 2 (superior), 
as quais apresentam espessuras similares, ou seja, cerca de quatro metros cada. $\mathrm{O}$ material da camada 1 é mais poroso (Fig. 1 A e B), contém maior quantidade de grãos clásticos detríticos (quartzo, feldspatos e micas) de maior tamanho em relação à camada 2 (Fig. 2) e, conseqüentemente, sujeito a maior percolação de fluídos. Apresenta cor cinza esverdeado com bandamento pouco evidente e é formada por estratos de siltitos mais granulares e porosos, com pontos ou manchas escuras ricas em matéria orgânica que desaparecem entre 550 e $600{ }^{\circ} \mathrm{C}$, conforme testes de queima realizados, o material é intercalado por lentes e leitos de textura mais fina e homogênea, semelhante à dos estratos da camada 2.
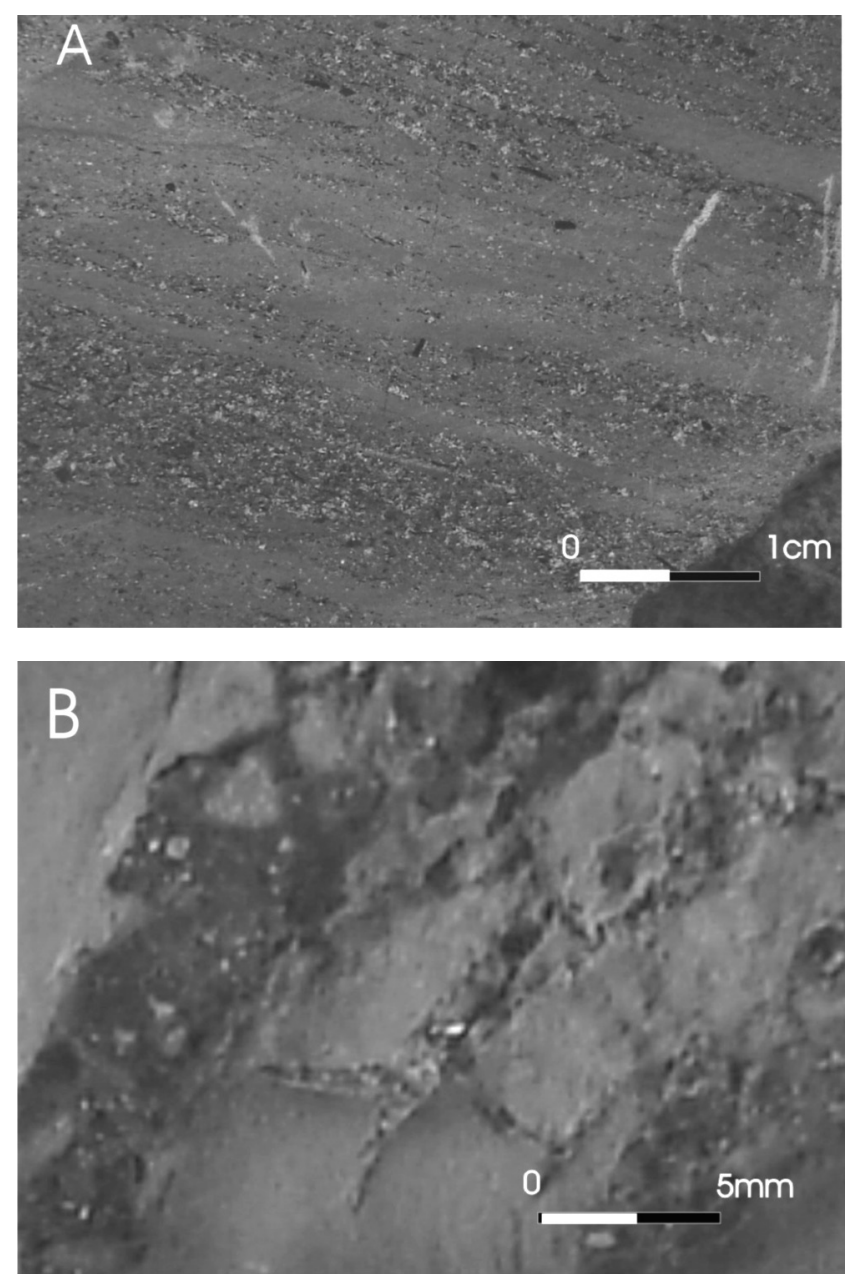

Figura 1: Rochas da camada 1 mostrando: (A) porosidade e alteração com formação de clorita, e (B) veios preenchidos com calcita e quartzo e manchas escuras com maior conteúdo de matéria orgânica.

[Figure 1: Claystone from layer 1 showing: (a) porosity and change with the formation of chlorite and (b) vein filled with calcite and quartz and dark spots with higher organic matter content.]

A caracterização mineralógica por difração de raios $\mathrm{X}$ mostrou como componentes principais: illita, clorita, estratificados irregulares, quartzo e feldspatos (Fig. 3A). Nas partes mais alteradas e fraturas da camada 1 foram identificados também: calcita, hematita, clorita expansiva,
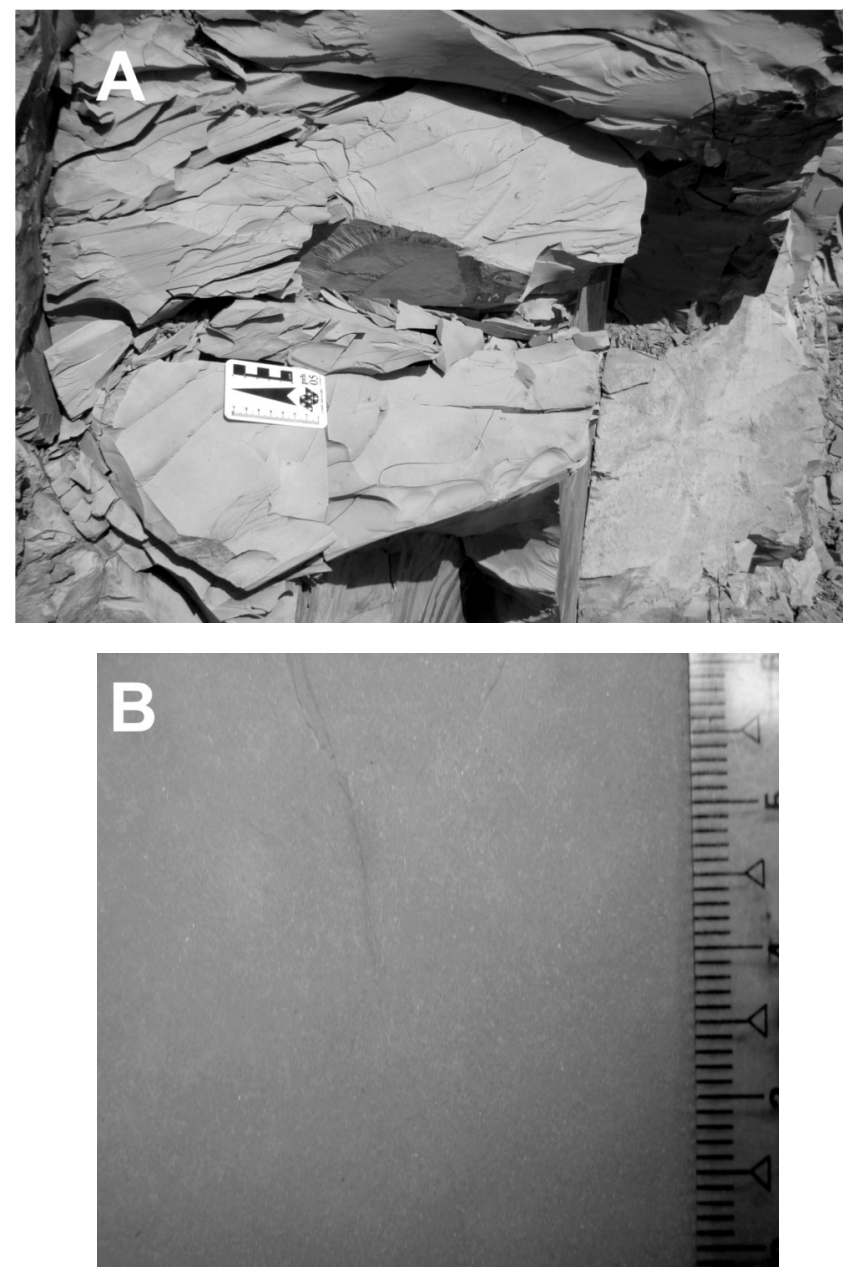

Figura 2: Rochas da camada 2 mostrando: (A) afloramento em bancada de mineração e (B) superfície de amostra estudada. Em ambas as imagens observa-se maior homogeneidade composicional e textura mais fina em relação ao material da camada 1 .

[Figure 2: Sample from layer 2 showing: A) outcrop in bench mining and $(B)$ surface sample. In both images there was a greater compositional homogeneity and finer texture than the material layer 1.]

apatita e anatásio. Na Fig. 3A observa-se que a proporção de argilominerais cristalinos entre as duas camadas não é muito diferente, porém o quartzo e feldspato apresentam maior altura de pico na camada 1. A maior alteração desta camada se reflete nas diferenças mostradas na fração menor que $2 \mu \mathrm{m}$ (Fig. 3C), em relação à camada 2 (Fig. 3B), que evidencia a percolação de fluídos mais intensa, resultando em maior concentração de minerais de textura grossa com picos bem definidos na fração fina.

Observações microcópicas, por luz transmitida, de seções delgadas obtidas de amostras representativas de ambos os estratos e de veios e descontinuidades deposicionais, forneceram dados texturais e mineralógicos, que complementaram os obtidos por difração de raios X. Para a visualização e determinação do material encontrado em algumas fraturas, além das secções delgadas normais, foi realizada imersão de fragmentos micrométricos, bem como do resíduo do ataque ácido, em líquidos com índice 

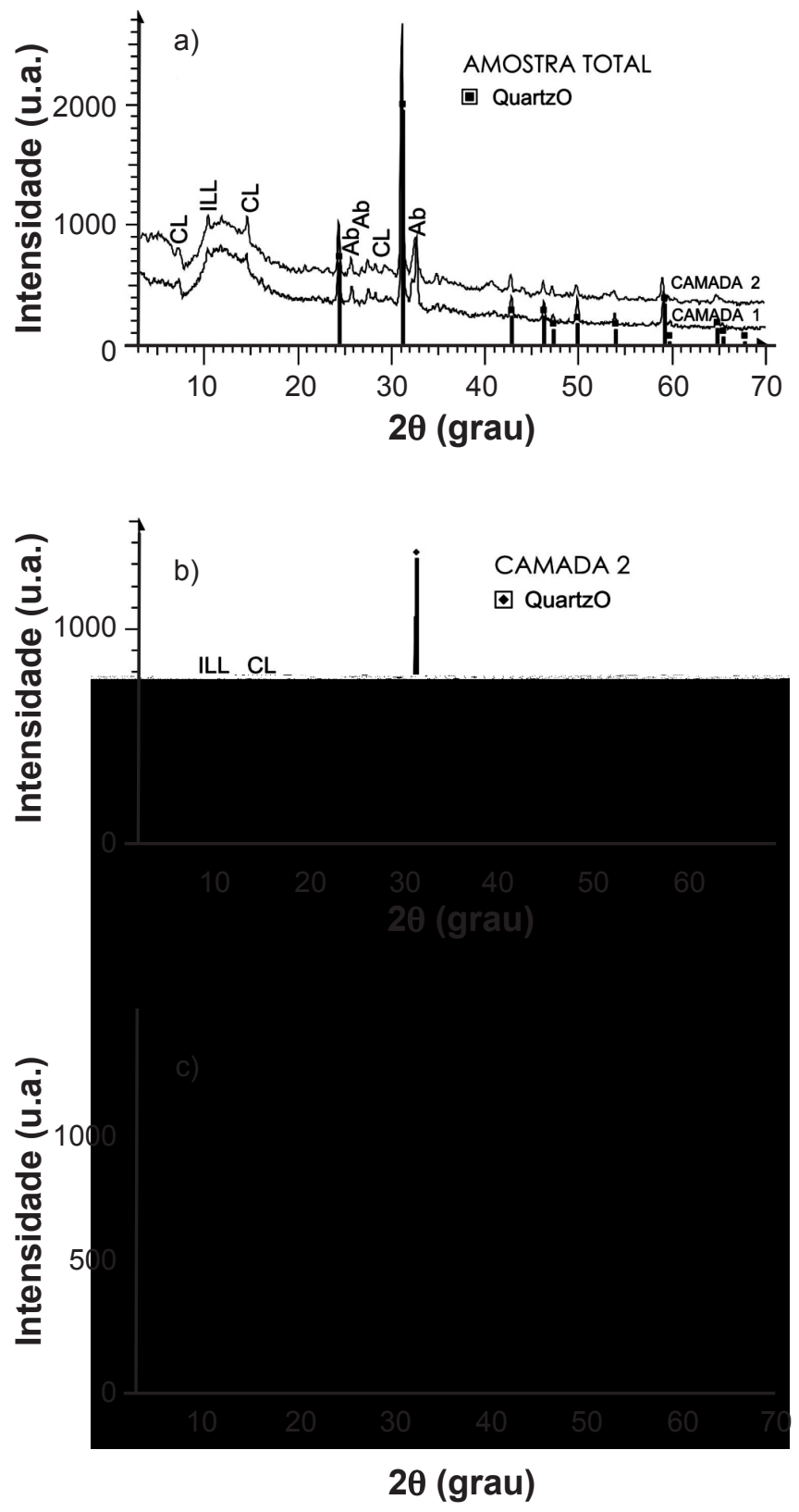

Figura 3: Gráficos de difração de raios $\mathrm{X}$ das amostras: A) total das duas camadas, B) fração menor que $2 \mu \mathrm{m}$ da camada 2 e C) fração menor que $2 \mu \mathrm{m}$ da camada 1 . Radiação Cok $\alpha$ e velocidade de $3^{\circ}$ (20)/min, onde $\mathrm{CL}=$ clorita; ILL=illita, $\mathrm{Ab}=$ albita (representando os feldspatos).

[Figure 3: Plots of X-ray diffraction of samples: A) the total of two layers, $B$ ) less than $2 \mu \mathrm{m}$ fraction of layer 2 and $C)$ less than $2 \mu \mathrm{m}$ fraction of layer 1. CoK $\alpha$ radiation and speed of $3^{\circ}(2 \theta) /$ min, where $C L=$ chlorite; $I L L=$ illite, $A b=$ albite (representing the feldspars).]

de refração conhecido, desta forma identificou-se como minerais detríticos: quartzo (5 a 40\%), feldspatos (2 a $15 \%$ ), fragmentos fósseis fosfáticos e silicosos (traços a $30 \%$ ), filossilicatos (biotita, muscovita e clorita) (1 a 3\%), minerais pesados (menos de 1\%). Como diagenéticos e/ ou remodificados pela diagênese constatou-se a presença de: illita (25 a 85\%), feldspatos alcalinos (traços a 20\%), calcedônia/quartzo (traços a 10\%), clorita (traços a 15\%) e filossilicato verde (traços a 10\%), carbonato (traços a $15 \%$ ), hematita e hidróxidos de ferro (2 a $8 \%$ ), anatásio (traços). O filossilicato verde apresenta leve pleocroísmo e birrefringênica moderada, sendo interpretado como interestratificado com base nos dados de difração de raios $\mathrm{X}$. Opticamente constatou-se que a camada basal possui maior heterogeneidade textural e composicional gerando bandamento difuso, maior riqueza em quartzo e feldspatos detríticos, que também exibem maior dimesão média em relação à camada sobreposta (Fig. 4A). Também se observou que os fragmentos de origem orgânica são mais frequentes
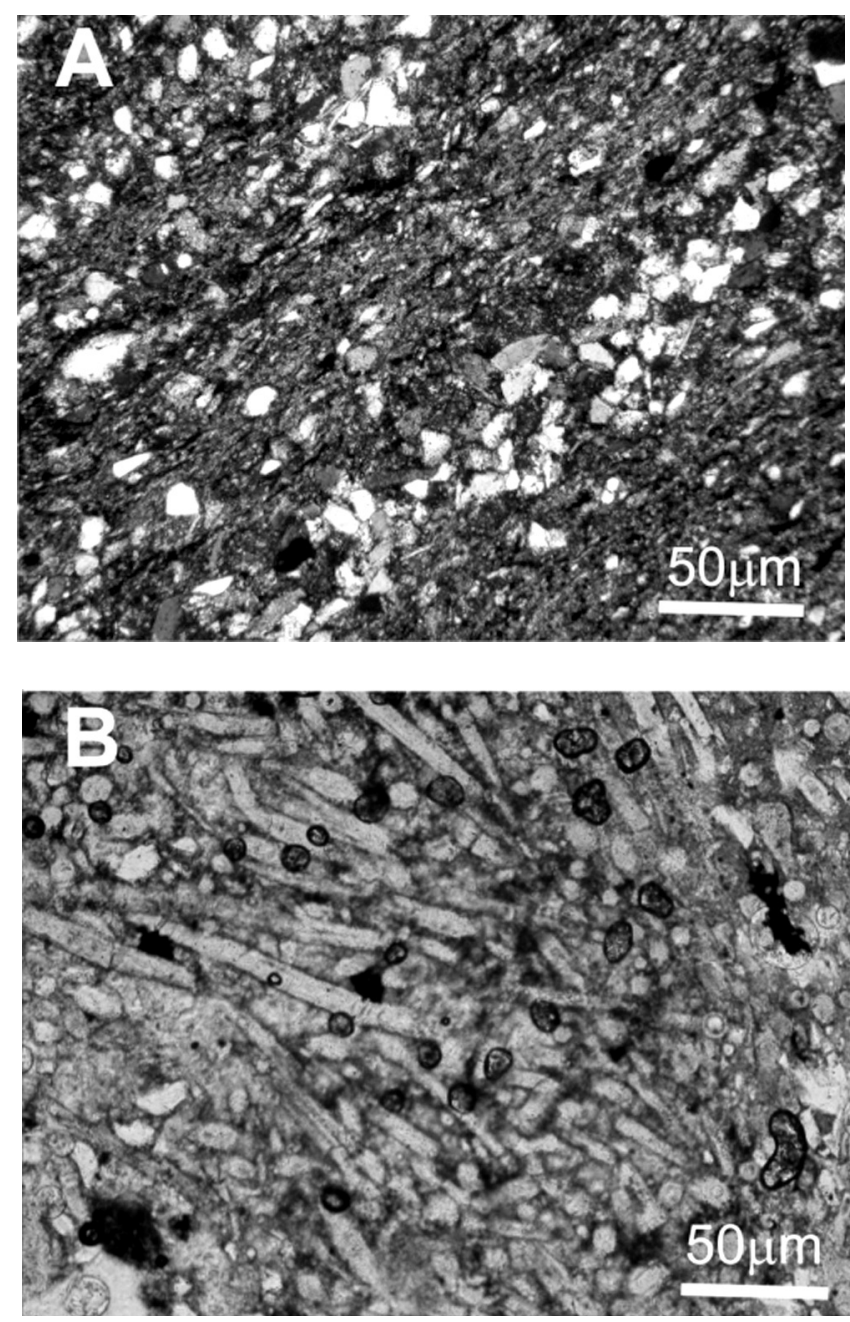

Figura 4: Fotomicrografias dos materiais estudados pertencentes a camada 1 (basal). A) aspectos gerais do material ao microscópio óptico, luz transmitita e polaróides cruzados. Observa-se a predominância de illita e faixas ricas em quartzo e feldspatos detríticos. B) Microfósseis tubulares encontrados na amostra e em toda a extensão da Formação Corumbataí. Imagem obtida com polaróides paralelos.

[Figure 4: Photomicrographs of the studied materials. A) general aspects of the material under an optical microscope, with crossed Nicols. There is a predominance of illite and tracks rich in detrital quartz and feldspar. B)Tube-shaped microfossils found in the sample and another places of Corumbatai formation]. 
na camada basal, sendo bem maiores que os grãos detríticos terrígenos e constituídos dominantemente por fosfato de cálcio e quitina (especialmente nos estratos inferiores). Destaca-se um tipo de micro fóssil silicoso (calcedônia/ quartzo) ou carbonático (raramente), que possui a forma de bastonete e chega a ser o principal componente de um estrato, de aspecto arenoso, presente na camada 1 (Fig. 4B).

A fotomicrografia obtida de seção delgada representativa da camada 2 (Fig. 5) evidencia a maior homogenidade textural e granulação mais fina que a da camada basal. Está composta basicamente por illita (chega a ter mais de 80\%), que apresenta granulação média entre 4 e $10 \mu \mathrm{m}$ e orientação segundo o acamamento sedimentar, envolvendo grãos clásticos terrígenos dispersos aleatoriamente. Nesta camada pode ocorrer ainda pequena quantidade de clorita dispersa ou em concentrações difusas lenticulares, cristais minúsculos de hematita dispersos homogeneamente e dispostos em trilhas ou formando delgados filetes e, esporadicamente, fragmentos fósseis (em especial coprótilos) individualmente isolados ou dispersos e, localmente, formando leitos descontínuos delgados (bone beds) constituidos por fragmentos de ossos, dentes, escamas, coprólitos, etc.

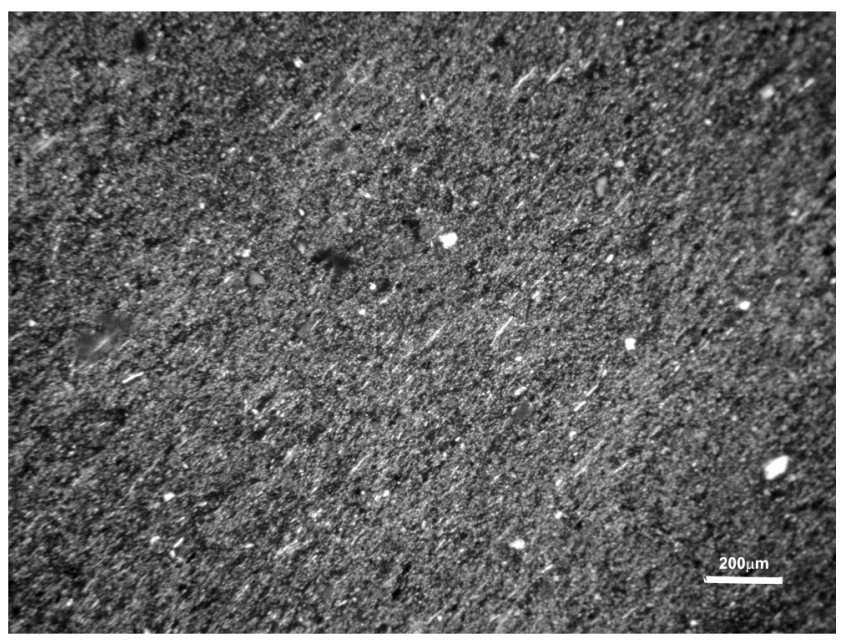

Figura 5: Fotomicrografia de secção delgada de material representativo da camada 2 constituido basicamente por filossilicatos finos orientados (illita, algumas palhetas de mica detrítica e poucas palhetas de clorita dispersas) com pequenos clastos terrígenos (quartzo e secundariamente feldspatos). Imagem obtida com luz transmitida e polarizadores cruzados.

[Figure 5: Photomicrograph of thin section of material representative of the second layer. This basically consist of thin oriented phyllosilicates (illite, some flakes of mica and detrital few scattered flakes of chlorite) with minor terrigenous clasts (quartz and feldspar secondarily). Image obtained with transmitted light and crossed polarizers. (Base figure: $2.1 \mathrm{~mm}$ ).]

O teor de carbono orgânico em amostras das duas bancadas variou de 0,50 a $0,56 \%$, maior que nos extratos usados na indústria cerâmica (menor que $0,20 \%$ ). A determinação do carbono orgânico de uma amostra obtida raspando as manchas escuras contidas em amostras da camada 1 resultou em $1,41 \%$ confirmando sua maior concentração e heterogeneidade, devido à maior porosidade da amostra. A camada 2, por seu teor de illita e clorita, conteúdo de matéria orgânica e textura fina e homogênea, reúne os requisitos necessários para expandir em altas temperaturas, entretanto, testes foram realizados com amostras de ambas camadas, constatando-se que o material poroso e/ou mais rico em clastos terrígenos, dominantes na bancada 1 , não retém os gases, conforme era previsto.

Desta forma, os testes de expansão foram realizados com o material homogêneo de textura fina da camada 2 , sendo que após a britagem foram gerados $7 \%$ de resíduo de fragmentos menores que $3 \mathrm{~mm}$. A Secagem prévia é importante para evitar que o vapor de água dentro dos fragmentos vaporize violentamente explodindo dentro do forno.

Corpos de prova de $7 \times 2 \times 1 \mathrm{~cm}^{3}$ preparados por prensagem com material moído da camada 2 (superior) mostraram considerável expansão, indicando que outros processos de fabricação de argila expandida podem ser aplicados ao mesmo material, sem necessidade de aditivos, permitindo também a utilização do resíduo da britagem.

Foram realizados testes preliminares de queima (Fig. 6) usando aproximadamente $100 \mathrm{~g}$ de fragmentos em forno de queima rápida de laboratório (estático) e temperaturas que variaram de 1020 a $1100{ }^{\circ} \mathrm{C}$, programado para $1 \mathrm{~min}$ de permanência na temperatura máxima, resultando em variação da densidade aparente até um valor mínimo de 0,5 $\mathrm{g} / \mathrm{cm}^{3}$. A temperaturas maiores que $1100{ }^{\circ} \mathrm{C}$ o grau de fusão parcial começa a ser excessiva aparecendo nas peças maiores (de menor densidade), uma leve deformação da superfície arredondada, configurando o limite de temperatura para as condições de queima dos fragmentos de $5 \mathrm{~cm}$ na dimensão máxima.

A partir dos resultados obtidos foi feita uma equivalência da temperatura entre os dois tipos de forno, estático e

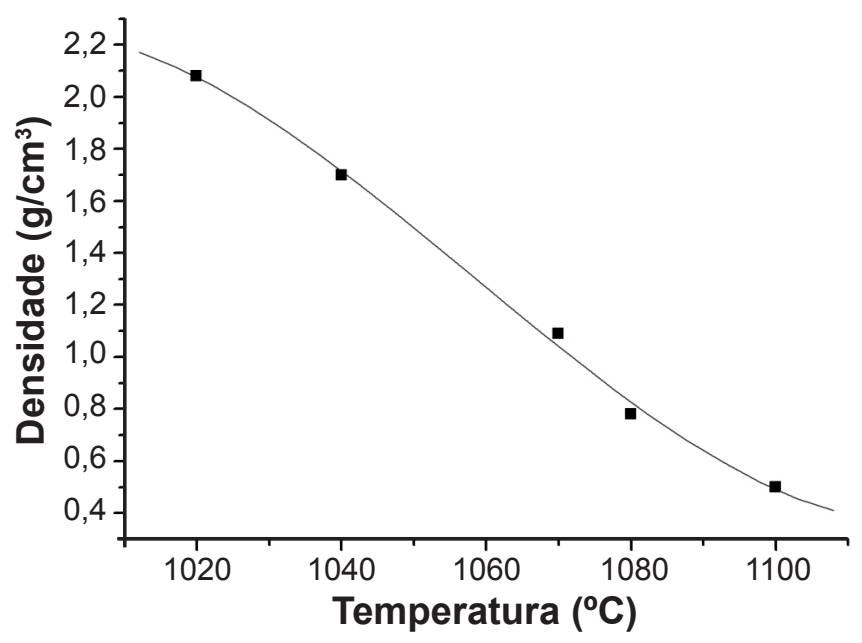

Figura 6: Variação da densidade dos fragmentos após queima, na etapa de testes, realizada em forno estático de queima rápida para laboratório.

[Figure 6: Variation of the density of the fragments after burning in the testing stage, carried out in fast firing furnace static of laboratory.] 
contínuo, de maneira a obter peças com a máxima expansão. $\mathrm{O}$ material britado e seco foi queimado a $1130{ }^{\circ} \mathrm{C}$ no forno contínuo, sendo mostrados na Fig. 7 o produto e o material de origem. Observam-se corpos arredondados de diferentes tamanhos com densidade média de $0,5 \mathrm{~g} / \mathrm{cm}^{3}$ uma vez que não foi feita separação por tamanho. É importante ressaltar que as partículas expandidas permaneceram "soltas", apesar de terem sido colocadas superpostas, o que é devido ao grau de fusão nessa temperatura e à alta viscosidade do fundido. Testes de absorção de água realizados mantendo os corpos imersos por meia hora resultaram em valores de aproximadamente $2 \%$, mostrando que os poros são fechados e que o valor obtido corresponde basicamente à retenção de água na superfície, considerando que não é totalmente lisa (Fig. 7).

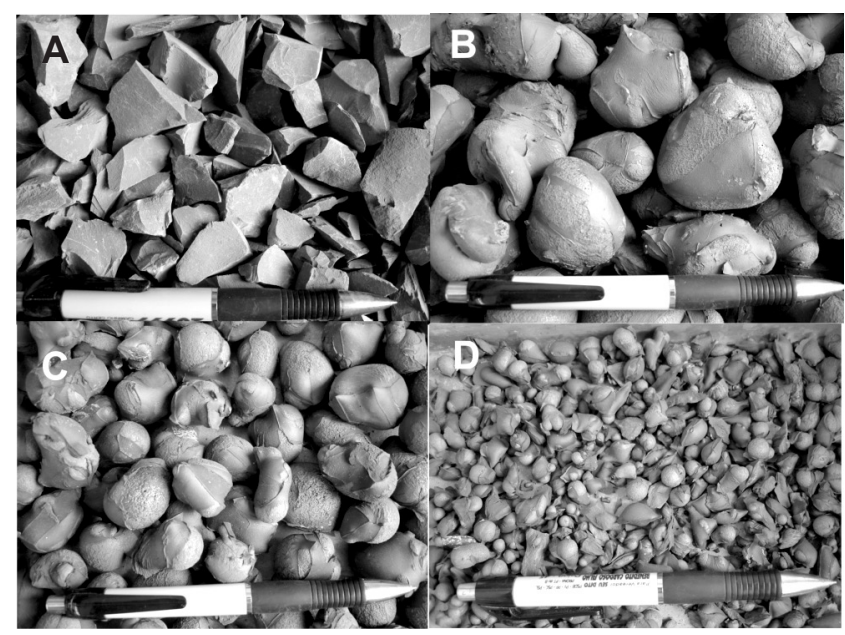

Figura 7: Fragmentos de rocha de diferentes tamanhos (A), depois de queimados em forno a rolos à temperatura máxima de $1030^{\circ} \mathrm{C}$ (B, C, D).

[Figure 7: (A) Rock fragments of different sizes, $(B, C, D)$ after burned in the oven furnace rolls of laboratory at maximum temperature of $\left.1030^{\circ} \mathrm{C}.\right]$

O aumento de volume aproximado é mostrado na Fig. 8 , onde a proveta (A) contém $300 \mathrm{~g}$ de fragmentos de argila no seu estado natural e em cada uma das outras (B-C-D-E) colocou-se a mesma massa de fragmentos expandidos, separados por tamanho. A figura também mostra a redução da densidade com o aumento do tamanho das peças de argila expandida, uma vez que os tamanhos são variados. Para tamanhos de fragmentos selecionados pode haver variação nas condições de queima.

O material expandido apresenta estrutura escoriácea, formada por vazios (poros), normalmente, esféricos a semi-esféricos de diferentes dimensões (micrométricos a milimétricos, podendo alcançar mais de $1 \mathrm{~cm}$ ), delimitados por material vítreo contendo grãos residuais (não fundidos) de quartzo e em menor quantidade de feldspatos e micas detríticas (Fig. 8). Não existe comunicação entre os poros (são fechados), fato comprovado pela imersão em água. Observação microscópica mostra que os filossilicatos diagenéticos (illita e clorita) foram quase que totalmente

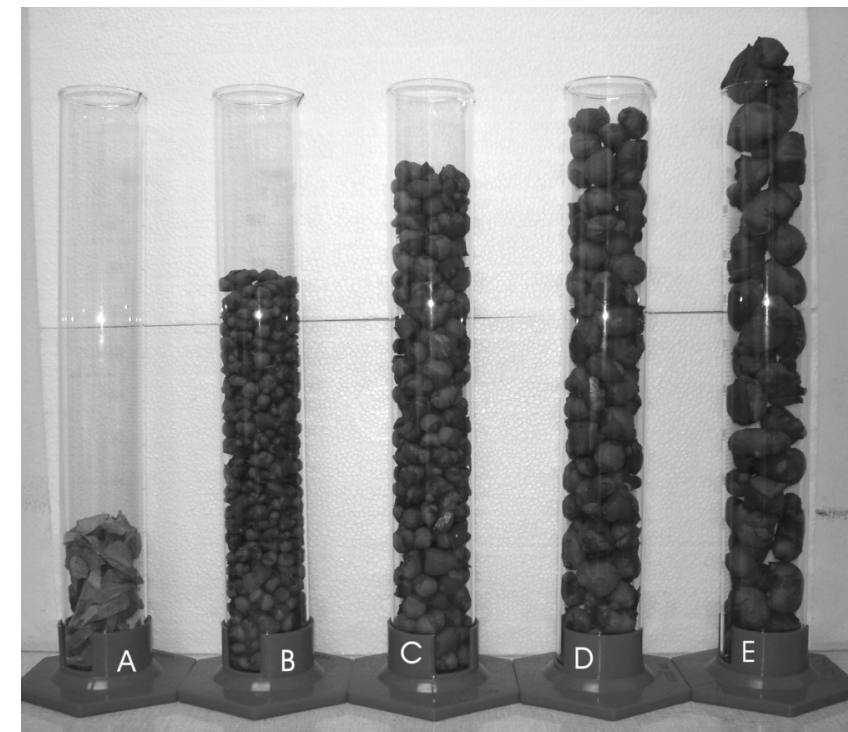

Figura 8: Variação de volume das peças (300 g) antes (A) e depois da queima (B, C, D, E) em forno a rolos para laboratório, a $1130{ }^{\circ} \mathrm{C}$ e separados por tamanho.

[Figure 8: Change in volume of the pieces (300 g) before (A) and after burning $(B, C, D, E)$ in the oven rolls for laboratory, at $1130^{\circ} \mathrm{C}$ and separated by size.]

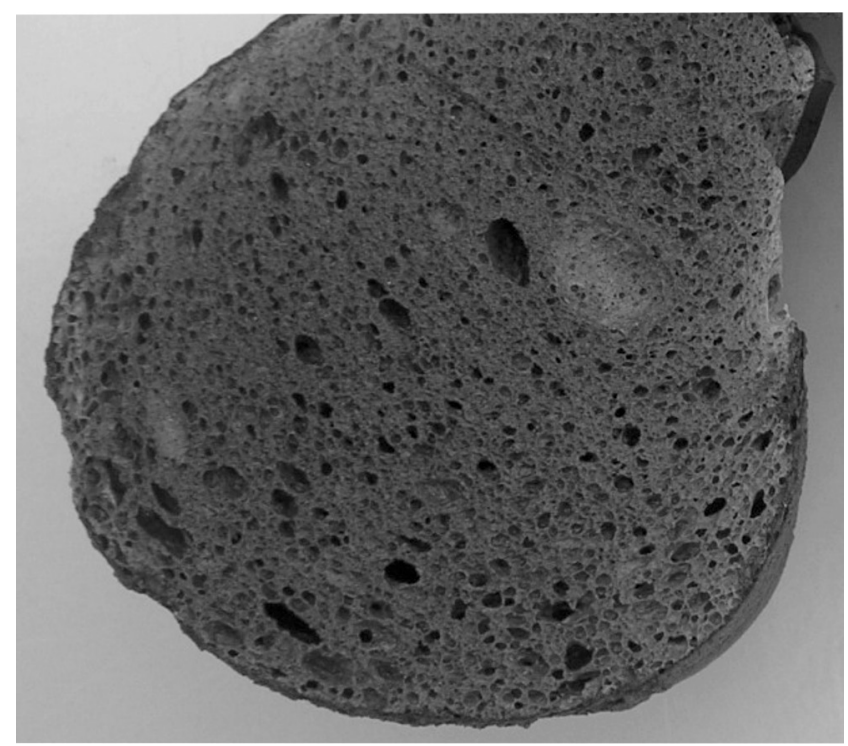

Figura 9: Fragmento expandido mostrando a estrutura de poros fechados com diferentes dimensões.

[Figure 9: Expanded fragment showing the structure of closed pores with different dimensions.]

destruídos juntamente com parte dos cristais de feldspatos e quartzo, resultando em fundido de grande viscosidade.

\section{CONCLUSÕES}

A matéria-prima da camada 2, que apresenta cerca de 4 $\mathrm{m}$ de espessura, possui características naturais ótimas para fabricação de argila expandida para usos diversos, podendo inclusive aproveitar-se o material fino resultante da britagem, 
depois de moído, para produzir bolinhas/blocos de tamanhos pré-determinados. Estas características permitem projetar a possibilidade de fabricação de argila expandida com custo sensivelmente inferior ao disponível atualmente no mercado brasileiro, em função da preparação da matéria-prima ser mais simples, visto que possui naturalmente os requisitos necessários. Em termos ambientais a geração de resíduos seria mínima, se devidamente planejada. Este material é relativamente abundante e atualmente não tem uma utilidade definida, uma vez que a indústria cerâmica exclui este nível por seu teor excessivo de carbono orgânico. Permite a obtenção de um produto com densidade aproximada de $0,5 \mathrm{~g} / \mathrm{cm}^{3}$ ou menor, semelhante ou melhor ao preparado através de pelotização/extrusão cujo processo eleva os custos de produção; Esta baixa densidade proporciona um rendimento maior que $300 \%$ causando menos desgaste nos meios de transporte quando comparado à brita. A densidade das partículas pode ser controlada variando a temperatura máxima, tempo de permanência no forno, tamanho e quantidade de fragmentos da rocha; Pode ser fabricado tanto em fornos rotativos como em fornos contínuos movidos a rolos, sendo que para aplicação deste último processo, podem ser adaptados fornos que ficaram obsoletos após a aquisição de equipamentos de última geração pelas indústrias cerâmicas de revestimentos, necessitando de estudos sobre a viabilidade econômica. Conforme mostrado na Fig. 5, uma mesma temperatura permite expansão de fragmentos de tamanho variado, permitindo a seleção do tamanho dos fragmentos tanto antes quanto depois da queima. Com o produto desta matéria-prima pode ser obtido agregado leve de excelente qualidade envolvendo custos menores.

\section{AGRADECIMENTOS}

À FAPESP e ao CNPq pelo financiamento da pesquisa.

\section{REFERÊNCIAS}

[1] E. J. Milani, Evolução tectono-estratigráfica da Bacia do Paraná e o seu relacionamento com a geodinâmica fanerozóica do Gonswana Sul-ocidental, Tese Dr., Instituto de Geociências da Universidade Federal do Rio Grande do Sul, Porto Alegre, RS (1997) 255 p.

[2] F. F. M. Almeida, O. Barbosa, Geologia das quadrículas de Piracicaba e Rio Claro, Boletim Divisão de Geologia e Mineralogia - Departamento Nacional de Produção Mineral, Rio de Janeiro, RJ 143 (1953) 1.

[3] O. Barbosa, F. A. Gomes, Pesquisa de petróleo na Bacia do Rio Corumbataí, Estado de S. Paulo, Boletim da Divisão de Geologia e Minas - DNPM, Rio de Janeiro, RJ 171 (1958) 1.

[4] S. Petri, A. M. Coimbra, Estruturas sedimentares das formações Irati e Estrada Nova (Permiano) e sua contribuição para a elucidação dos seus paleoambientes geradores, Brasil, V Cong. Latino-americano de Geologia, Actas 2 (1982) 353.

[5] R. Rohn, The Upper Permian of the Paraná Basin, Brazil: a new stratigraphic approach, Gaea Heidelbergensis, Heidelberg 3 (1997) 290.

[6] A. N. Ramos, M. L. L. Formoso, Clay mineralogy of the sedimentary rocks of the Paraná Basin, Brazil, Rev. Bras. Geoci. 6, 1 (1976) 15.

[7] R. Rodrigues, L. P. Quadros, Mineralogia das argilas e teor de boro das formações paleozóicas da Bacia do Paraná, 29 Cong. Bras. Geol., Soc. Bras. Geologia, Ouro Preto, MG 2 (1976) 351.

[8] S. R. Christofoletti, M. M. T. Moreno, A. Batezelli, Análise de Fácies da Formação Corumbataí (Grupo Passa Dois - Bacia do Paraná, Neopermiano), com Vista ao Emprego na Indústria de Revestimento Cerâmico, Rev. Bras. Geoci. 36, 3 (2006) 488.

[9] A. Zanardo, C. D. Roveri, M. N. de S Costa, M. M. T. Moreno, Evidências de Hidrotermalismo na Formação Corumbataí, na Região de Rio Claro (SP), 43 Cong. Bras. Geol., Coletânea de Trabalhos Completos, Aracaju, Sociedade Brasileira de Geologia 1 (2008) 355.

[10] A. Zanardo, M. M. T. Moreno, C. D. Roveri, R. R. da Rocha, Critérios de Avaliação de Intemperismo e sua Relação com as Propriedades Tecnológicas das MatériasPrimas Cerâmicas da Formação Corumbataí (Região de Rio Claro - SP), $53^{\circ}$ Cong. Bras. Ceram., Guarujá, SP 1 (2009) 1.

[11] M. N. S. Costa, A. Zanardo, M. M. T. Moreno, Características Químicas Mineralógicas e Cerâmicas das Argilas da Mina Granusso, Cordeiropolis (SP), Ceram. Ind. 12, 1/2(2007) 22.

[12] C. D. Roveri, A. Zanardo, M. M. T. Moreno, Variação da cor e propriedades cerâmicas com o aumento da temperatura de queima de uma argila proveniente da formação Corumbataí, região de Piracicaba (SP), Cerâmica $\mathbf{5 3}, 328$ (2007) 436.

[13] R. R. Rocha, A. Zanardo, M. M. T. Moreno, Estudo do comportamento reológico de barbotinas preparadas com argilas da Formação Corumbataí utilizadas no pólo cerâmico de Santa Gertrudes (SP), Cerâmica 54, 331 (2008) 332.

[14] M. M. T. Moreno, A. Zanardo, J. R. J. Imenez-Rueda, XLIII Cong. Bras. Geol., Soc. Bras. Geologia - SBG, Aracaju, SE 1 (2006) 229.

[15] P. Souza Santos, Ciência e Tecnologia de Argilas, Ed. Edgard Blücher Ltda., SP 2 (1992) 438.

[16] C. F. Gomes, Argilas: O que são e para que servem, Fundação Calouste Gulbenkian, Lisboa, Portugal (1986) 365.

[17] M. L. Jackson, Soil Chemical Analysis, Prentice Hall, New Delhi, India (1967) 219.

(Rec.01/04/2011, Ac. 16/10/2011) 